\title{
EX SITU TREATMENT OF ORGANIC WASTES OR OIL-IMPACTED SOIL USING A SMOLDERING PROCESS
}

\author{
GABRIEL SABADELL ${ }^{1}$, GRANT SCHOLES ${ }^{1}$, DAVID THOMAS ${ }^{2}$, CODY MURRAY ${ }^{1}$, PAUL BIRETA ${ }^{2}$, \\ GAVIN GRANT $^{1} \&$ DAVE MAJOR ${ }^{1}$ \\ ${ }^{1}$ Savron, US \\ ${ }^{2}$ Chevron Energy Technology Company, US
}

\begin{abstract}
An innovative treatment technology has been developed for the treatment of organic wastes. The technology utilizes the waste itself as the primary fuel for treatment via smoldering combustion. The process requires a heat source solely to initiate treatment. Once the process is initiated, treatment is sustained by continuously supplying air. The process may be implemented either ex situ or in situ, with this paper focused on the ex situ application for waste treatment or remediation purposes. This ex situ smoldering combustion treatment technology has been effectively demonstrated at field-scale for the management of oily wastes (e.g. tank bottom sludge, clarifier or pit sludge) and oil-impacted soil. Furthermore, the ex situ application has been demonstrated at pilot scale for domestic and commercial wastes (e.g. biosolids or sanitary sludge, kitchen grease) and ongoing development of the technology indicates other chemicals or wastes may also be effectively treated. If the waste is a combustible organic, or may be mixed with combustible organics, it is possible it may be treated with this technology. The Hottpad configuration is the culmination of collaborative research and technology development between Savron and Chevron. Each Hottpad unit has an engineered and trafficable working surface (or pad) equipped with a heat source to initiate the reaction, and an air distribution system to sustain the smoldering combustion that then propagates upward in the direction of air flow. Each Hottpad system is equipped with an emissions collection and treatment system, as necessary. The technology is cost-effective, robust, and applicable for a broad range of materials. Furthermore, the design is scalable and may be sized to meet project needs (from large centralized facilities, to smaller mobile treatment systems for remote sites). The Hottpad technology is very robust, both in terms of the range of materials that can be treated and from an operations perspective; it is costeffective; it may be implemented on site, reducing off-site transportation, eliminating safety concerns, and reducing the overall remediation carbon footprint; and the treatment will meet stringent treatment or remediation requirements.
\end{abstract}

Keywords: smoldering combustion, remediation, oil-impacted soil, thermal oxidation, self-sustained.

\section{INTRODUCTION}

The concept of smoldering combustion for waste treatment purposes is relatively new, with the first paper on this topic published in 2005 [1]. Subsequent work expanded the concept of smoldering combustion for remediation purposes, both in situ and ex situ [2]-[5]. The treatment process leverages the waste content as the fuel for sustaining treatment via smoldering combustion. Smoldering is a non-flaming combustion process that occurs on the surface of a condensed (i.e., solid or liquid phase) fuel, converting organic material primarily into heat, carbon dioxide, and water. Within a predominantly inert porous matrix such as sand or soil, the heat is retained within the matrix and the combustion is sustained, provided there is sufficient oxidant (e.g. oxygen in air) and fuel (e.g. oil or organic waste).

Through more than five years of research and development, an alternative configuration for implementing ex situ smoldering combustion for the treatment of organic waste or remediation of oil-impacted soil was developed. Testing and technology development efforts to date proved the process to be robust and effective for a wide range of waste materials (e.g. waste type and concentration, solid matrix composition and grain size, or 
water content). Most of the ex situ treatment work has been with oily wastes (e.g. tank bottoms, clarifier sludge) or crude oil-impacted soil (OIS), but laboratory and prototype scale testing has also demonstrated treatment efficacy for other materials (e.g. biosolids [6], sanitary waste [7], vegetable oil [8], [9], tires [1]). The thermal oxidation that occurs during smoldering combustion nearly completely destroys the contaminants or waste material, rendering a clean solid matrix material that may either be recycled to treat more waste, or may be beneficially used (e.g. as construction backfill) as opposed to requiring disposal or management as a waste material.

\section{DESCRIPTION AND APPLICATION}

The subject technology treats a pile of material containing organic waste. The pile is placed upon an engineered working surface (referred to as the Hottpad configuration). The waste containing material may either be OIS or a combustible organic waste blended into a porous matrix (e.g. coarse sand). To initiate treatment, heat is applied at the base of the pile. Concurrent with heating, air is injected at the base of the pile such that the air flows vertically upward through the pile. Heat is applied for a relatively short duration, until temperatures within the bottom-most portion (i.e., $2-3 \mathrm{~cm}$ ) of the pile are sufficiently high to initiate and sustain the smoldering combustion reaction. The temperature at which smoldering is initiated varies according to waste type and may be in the range of 200$300^{\circ} \mathrm{C}$ [5]. Once smoldering has commenced, the heat source may be turned off. Air is continuously injected through the base of the pile to supply the oxygen necessary to sustain the smoldering reaction, propagating the treatment front vertically upward in the direction of air flow. Treatment within the pile following start-up (i.e. after the heat source has been shut off) is self-sustaining since the smoldering continues in the absence of external energy input [2]. The treatment front is relatively thin with pre-heating in advance of the reaction front (both convection and conduction), and the higher temperature smoldering front itself. The treatment consists of multiple simultaneous processes or reactions, including volatilization in advance of the treatment front, pyrolysis and thermal oxidation within the smoldering treatment zone, with most of the waste removed due to oxidation.

The treatment pile consists of the waste containing material which is then covered with an oil- or waste-free porous matrix (typically previously treated material). The additional cover material is placed atop the waste material for improved flow and treatment control. Emissions from the pile are collected and may be treated to meet appropriate air regulations. Fig. 1 depicts a cross-section of the Hottpad treatment process.

A Hottpad treatment system consists of the following basic components:

- One or more Hottpad modules, upon which the material to be treated is placed, comprise the engineered working surface. The dimensions of the working surface are scalable, since multiple modules may be placed together. The modules provide a trafficable working surface, through which air may be injected upwards into the material that is to be treated. In addition, within each module, is a heat source for supplying the energy necessary to initiate the treatment process. Electrical heaters were used for the two demonstration systems discussed here.

- An air supply system to the Hottpad system. Since multiple Hottpad modules were used for the demonstration system, the air supply system includes a blower and manifold to distribute and control flow to each Hottpad module.

An emissions collection system consisting of an extraction blower and an impermeable cover. Collectively, this essentially creates a vacuum hood for emissions containment and capture. The system includes piping and 


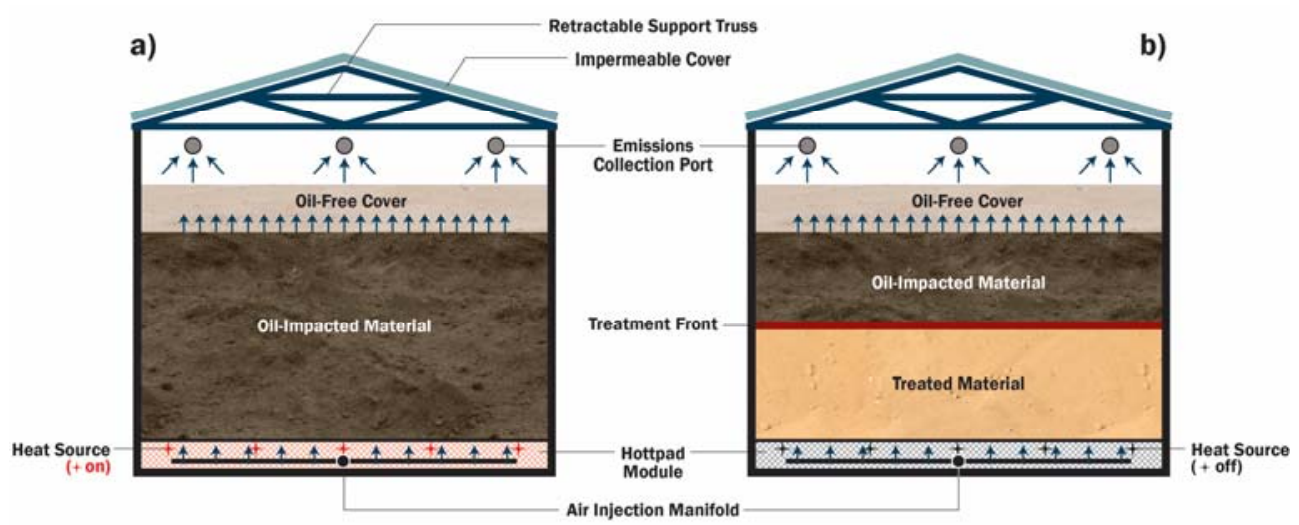

Figure 1: Cross-section of Hottpad Treatment Unit. (a) During start-up; and (b) During sustained treatment.

instrumentation to control flow and maintain emissions capture. The emissions collection system was equipped with Continuous Emissions Monitoring System (CEMS) and the emissions were vented through a stack.

- A power supply for the treatment system equipment. The field demonstration system was completely powered by electricity, utilizing a mobile generator were used as the power supply for the heaters, blowers, instrumentation and controls.

- Process control and instrumentation for system operation. This incorporates all the electrical distribution cables, instrument wiring, and control wiring for the Hottpad heating elements, injection blower(s), and extraction blower. It also includes the distribution and control panels such as the Programmable Logic Control (PLC) and the heater control panel.

The treatment is performed as a batch process, with materials handling (i.e. mixing, loading, unloading) done with readily available heavy equipment (e.g., excavator or frontend loader) for relatively rapid transitioning between batches.

Treatment of organic waste using the Hottpad system requires blending of the waste with a relatively inert porous medium (e.g. coarse sand or crushed rock). The blended material is then placed onto the Hottpad for treatment.

The system described here was the initial scale-up from prototype testing (i.e., approximately $1 \mathrm{~m}^{3}$ of blended material per treatment cycle) to field scale (i.e., $150-200 \mathrm{~m}^{3}$ of blended material per treatment cycle). The system was constructed for treating crude oil sludge from a clarifier and surge pond at a former refinery/terminal facility. The system consisted of six Hottpad modules to create an approximately $78 \mathrm{~m}^{2}$ working surface. Each module had an air injection pipe and was equipped with six electrical heaters.

Two air injection systems were used, each providing the air supply to 3 Hottpad modules. Initially, earthen berms were constructed around the perimeter to contain the sludge-solid blend. The emissions collection system was simply a perforated pipe placed atop the pile, covered with an impermeable chemical resistant tarp. An extraction blower operating at a flow approximately 1.5 times greater than the total air injection flow rate was used to capture the emissions from the treatment pile. Figs 2 and 3 show the basic set up at the site during the initial stages of on-site assembly. 


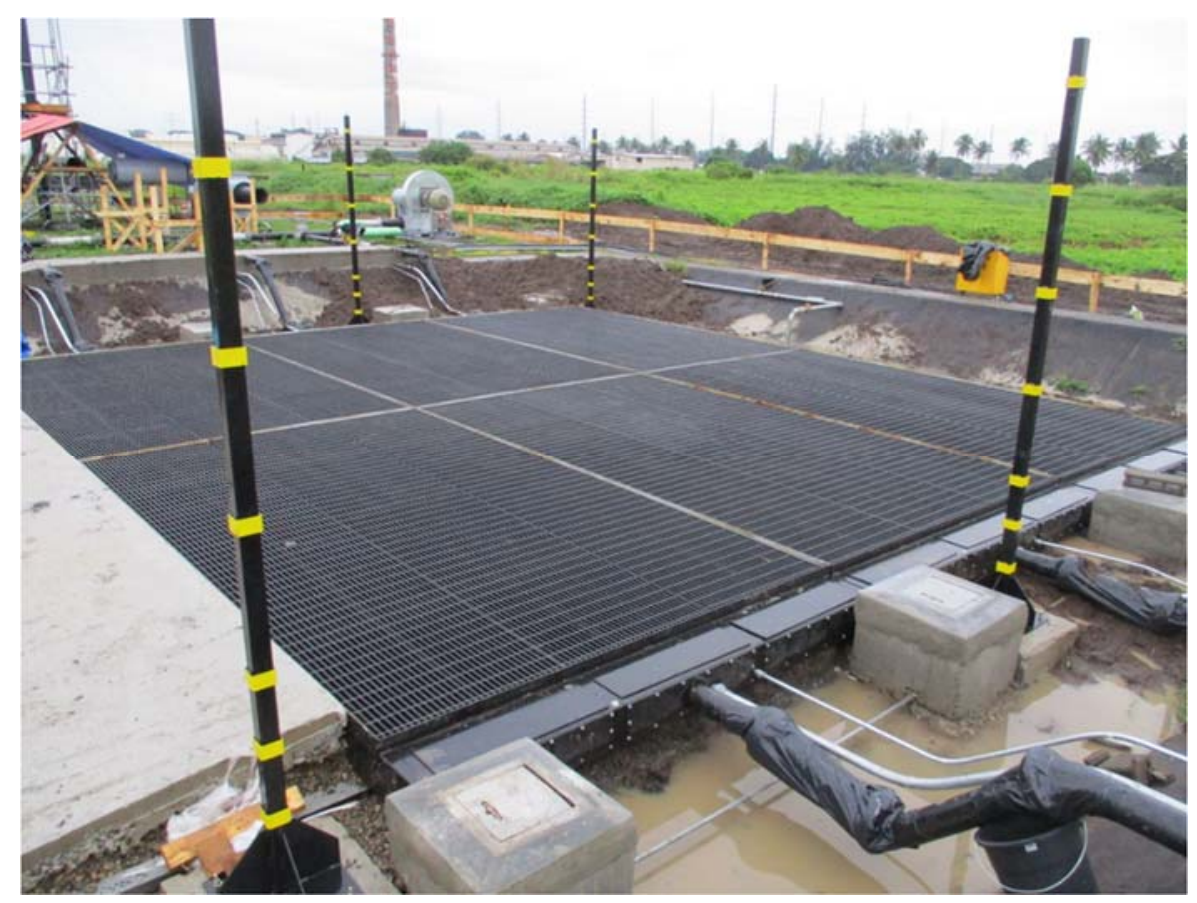

Figure 2: Six Hottpad module system.

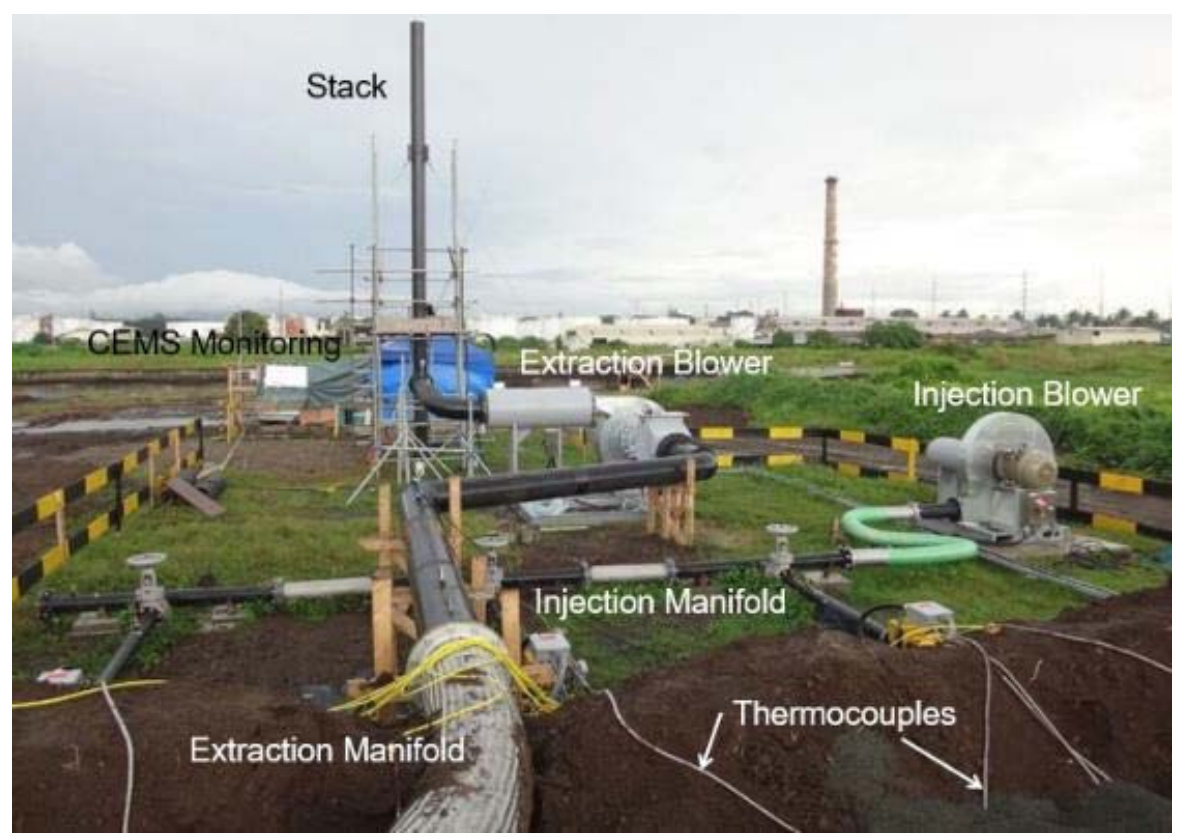

Figure 3: System air injection and emissions collection. 
Following initial operation, system modifications were made, including the addition of side walls (both for improving emissions containment system deployment and improving soil loading and unloading) and the integration of different emission treatment equipment (e.g. a scrubber, a granular activated carbon unit, and an ultraviolet photo-oxidation unit). The walls are equipped with a top-mount rail that supports a retractable cover. Figs 4 and 5 show the modifications that were incorporated into the system.

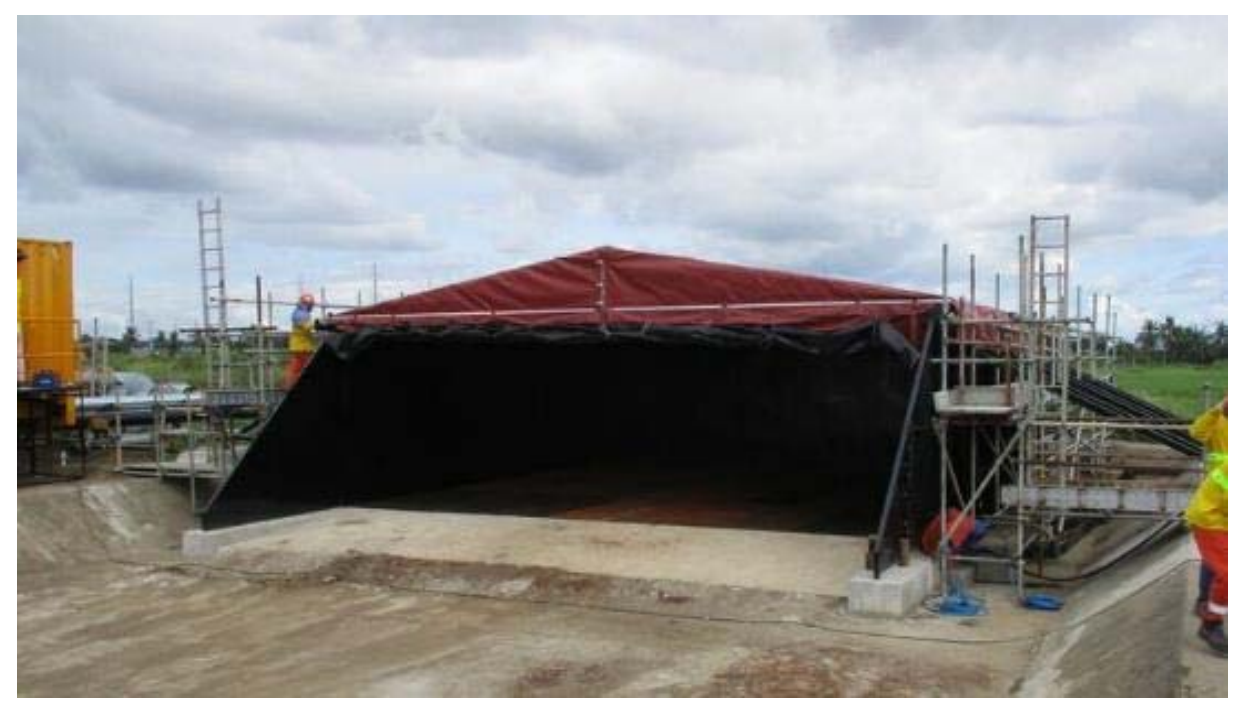

Figure 4: Following addition of walls and emissions collection tarp deployment system.

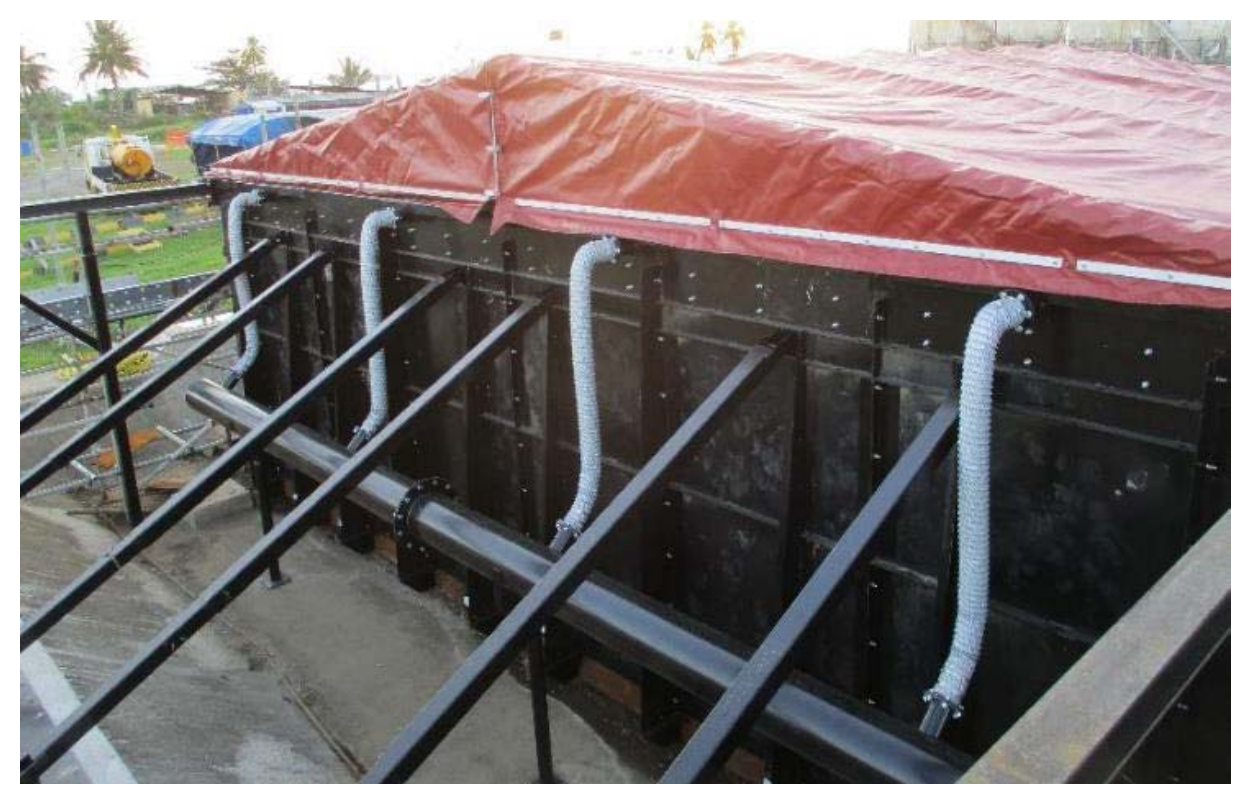

Figure 5: Rear wall, including the emissions collection manifold. 


\section{SUMMARY OF OPERATIONS}

The system was used to treat crude oil containing sludge from a secondary clarifier (effectively an oil water separator) and surge pond at a former refinery/terminal facility. The sludge from the surge pond was approximately $5.5 \% \mathrm{TPH}$ and up to $47 \%$ water; whereas the secondary clarifier sludge was $20 \% \mathrm{TPH}$ and similar water content as the surge pond.

The oily sludge was blended into a coarse crushed rock matrix to create the treatment blend. The blend ratio ranged from 1:3 parts by volume sludge:solid, down to 1:7 parts sludge to solid. Following blending of the sludge and solid matrix, composite samples were collected for TPH analysis. The blended material ranged from slightly over $13.5 \% \mathrm{TPH}$ to just below 3\% TPH. Moisture content in the blended materials was typically below $10 \%$ (closer to $5 \%$ ) since the solid matrix was extremely dry following treatment and then recycled for blending. However, for one of the initial runs, when the solid matrix was used for the first time, and following a heavy rainfall, the initial moisture content was close to $30 \%$. Pile heights ranged from $0.5 \mathrm{~m}$ up to $2 \mathrm{~m}$. A $0.5 \mathrm{~m}$ oil-free cover was placed overlying the treatment pile, prior to deploying the emissions collection system. The oilfree cover serves several purposes, including flow control and a matrix for capturing and treating any mobilized combustible materials.

During initial phase of operations, the temperature profiles within the pile was also monitored during treatment, as well as along the perimeter and walls. Thermocouples placed throughout the pile (both vertically and areally) and a data logger was used to collect temperature readings within the treatment pile. This data was used to assess time to ignition, monitor the treatment front propagation rate, and determine when pile treatment had completed. This information was then used to improve operations and has supported subsequent Hottpad system designs.

Basic operations require control of both injection and air flow rates, as well as the injection pressures within the Hottpad module plenums. Flows are balanced to maintain a flow velocity of less than $1 \mathrm{~cm} / \mathrm{s}$ through the pile yet maintaining an extraction rate 1.25 to 1.5 times the total injection flow. Extraction flow needs to be greater than the flow of injected air in order to ensure full emissions capture.

During operations, a Horiba combustion gas analyzer was used to continuously monitor the combustion gas composition (i.e., $\mathrm{CO}, \mathrm{CO}_{2}, \mathrm{SO}_{\mathrm{x}}, \mathrm{NO}_{\mathrm{x}} \mathrm{O}_{2}$, and VOCs) in the emissions collection system prior to treatment or venting from the stack. Periodically, additional gas samples were collected for chemical analysis of a range of compounds using EPA methods TO-15 or TO-3 Modified, or ASTM D 5504-12 to further assess the composition of emissions from the pile.

Following completion and once the pile was sufficiently cool, samples were collected from the treated pile for chemical analysis, primarily TPH and metals. GSD analyses were also performed to assess changes in the solid matrix due to treatment and materials handling. The treated material was reused to blend sludge for the subsequent batch.

\section{SUMMARY OF TREATMENT RESULTS}

In all cases, it was visually evident that treatment was virtually complete. Not only was the material completely dry, but the color had been transformed from a dark, blackish color, to light gray-reddish color. Fig. 6 is an illustration of how the matrix changed during treatment.

These results demonstrated the efficacy of the treatment process for oily sludge destruction, rendering a clean solid matrix that could be recycled during the treatment process. While the maximum sludge content was approximately $30 \%$ on a volumetric basis, 

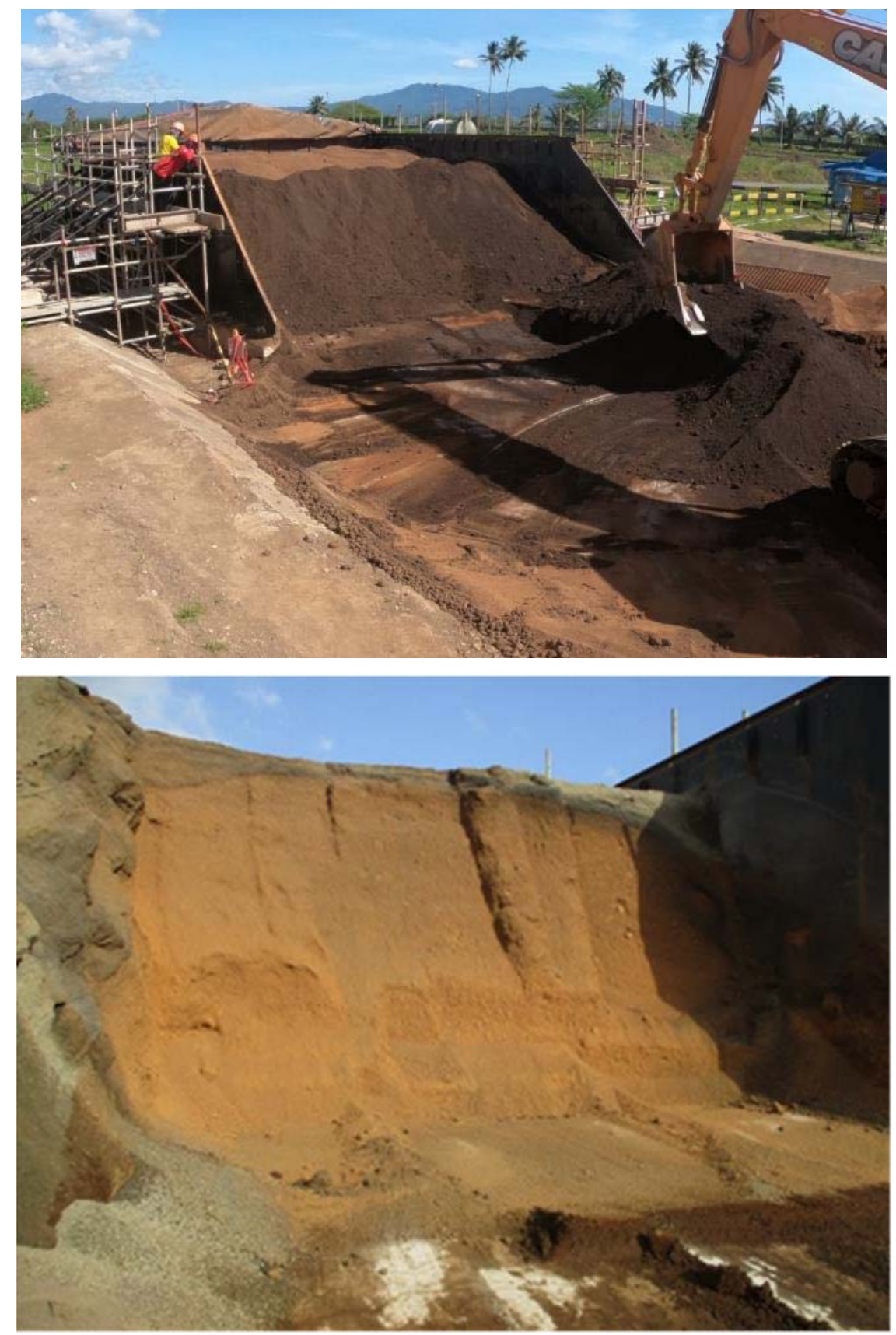

Figure 6: Prior to (top) and following (bottom) treatment.

results indicate an even higher sludge to solid blend ratio may be used in the future to increase treatment. In all cases, the treated material was dry and suitable to be reused for blending, with a treatment efficiency of greater than $97 \% \mathrm{TPH}$ removal, frequently greater 
than $99 \%$ efficiency. In almost all the post-treatment samples, the TPH concentration was below detection limits.

Maximum temperatures reached within the pile during treatment were greater than $650^{\circ} \mathrm{C}$, however, complete treatment was also noted even when the measured temperatures did not exceed $500^{\circ} \mathrm{C}$. Despite the elevated temperatures within the pile, wall temperatures did not exceed $150^{\circ} \mathrm{C}$, well within the operational parameters for the construction materials used.

Continuous emissions monitoring data indicated that while emissions from the pile contained potentially significant amounts of $\mathrm{CO}$ and VOCs, emissions at the stack met applicable regulations. Emissions monitoring and in-line sampling provided information to support the design of emissions treatment for future projects where more stringent emissions regulations may apply. With emissions collection system flows 1.25 times greater than the air injection flow, emissions from the top of the pile were effectively captured. The walls and integrated cover system improved the ratio of extraction to injection flow. Minimizing emissions collection flow is important for mitigating treatment costs, especially when operating in areas where costly emissions treatment may be required.

Ignition usually occurred within $8-10$ hours of start-up, and a $2 \mathrm{~m}$ tall pile was typically treated within approximately 4 days. Depending on whether the material can be unloaded while hot (i.e. temperatures above $300^{\circ} \mathrm{C}$ ) or whether time is required for the pile to cool, will be a significant consideration for determining system throughput. Initial water content did not seem to affect the treatment efficacy or overall treatment rate. That the process is robust and easily handled materials with high water content, distinguishes the Hottpad technology from other thermal treatment technologies (e.g. thermal desorption), which have practical and cost limitations with high water content materials.

For one of the batches, OIS from the terminal facility was used as the solid matrix for blending with oily waste. This batch processed similarly to the other batches using the crushed rock as the solid matrix. Due to be a finer material, the OIS having a relatively high clay and silt content, air flow and treatment rates were slightly lower, but the final treatment results were as effective. The treated OIS was accepted as being clean and subsequently used as backfill in the original excavation.

Ultimately, for this project, the cost of using Hottpad was considerably less than other sludge disposal alternatives, including removal from the pits for transport and disposal elsewhere. In addition, elimination of truck traffic, both on site and on local roadways, was a significant benefit for terminal operation and the local community.

\section{CONCLUSIONS}

The technology is effective for a broad range of oily wastes and easily treats heavier oils and crude oil sludge. The work performed during this project demonstrates that this technology may be applied to treat large volumes of oily or organic wastes. Properly selecting both the solid matrix and the waste:solid mixing ratio allows for more consistent and predictable treatment, simplifying operations and providing greater certainty of treatment costs. Another benefit of this technology is that multiple materials may be combined for simultaneous treatment, such as blending OIS and sludge.

The modular based system makes it easily scalable, as demonstrated by this project. Not only may the number of modules be adjusted to create the right size and configuration of working surface, but multiple systems may be operated in sequence to create a "continuous batch" processing facility to increase throughput. For example, because of this work, others have selected this technology for projects requiring the treatment of greater than 100,000 
$\mathrm{m}^{3}$ of sludge. Furthermore, the technology is fairly straightforward to implement, such that local operators may be trained quickly.

\section{ACKNOWLEDGEMENTS}

The authors would like to acknowledge the funding support provided by Chevron Environmental Management Company and the support and contributions made by Jorge Gabayet and the staff at Gudgeon Thermfire, Inc.

\section{NOMENCLATURE}

ASTM = ASTM International (formerly American Society for Testing and Materials)

CEMS $=$ Continuous Emissions Monitoring System

$\mathrm{CO}=$ Carbon Monoxide

$\mathrm{CO} 2=$ Carbon Dioxide

$\mathrm{E} \& \mathrm{P}=$ Exploration and Production (synonymous with "upstream")

EPA $=$ U.S. Environmental Protection Agency

$\mathrm{GAC}=$ Granular Activated Carbon

$\mathrm{GHG}=$ Greenhouse gas

$\mathrm{GSD}=$ Grain Size Distribution

$\mathrm{O} 2=$ Oxygen

OIS $=$ Oil-impacted soil

PLC $=$ Programmable Logic Controller

$\mathrm{NOx}=$ Nitrogen oxides

$\mathrm{SOx}=$ Sulfur Oxides

SVOCs $=$ Semi-Volatile Organic Compounds

$\mathrm{TC}=$ Thermocouple

TGA $=$ Thermogravimetric Analysis

$\mathrm{TPH}=$ Total Petroleum Hydrocarbons

VOCs $=$ Volatile Organic Compounds

\section{REFERENCES}

[1] Vantelon, J.P., Lodeho, B., Pignoux, S., Ellzey, J.L. \& Torero, J.L., Experimental observations on the thermal degradation of a porous bed of tires. Proceedings of the Combustion Institute, 30(2), pp. 2239-2246, 2005.

[2] Switzer, C., Pironi, P., Gerhard, J., Rein, G. \& Torero, J., Self-sustaining smoldering combustion: A novel remediation process for non-aqueous-phase liquids in porous media. Environmental Science \& Technology, 43(15), pp. 5871-5877, 2009. DOI: $10.1021 / \mathrm{es} 803483 \mathrm{~s}$.

[3] Pironi, P., Switzer, C., Gerhard, J., Rein, G. \& Torero, J., Self-sustaining smoldering combustion for NAPL remediation: Laboratory evaluation of process sensitivity to key parameters. Environmental Science \& Technology, 45(7), pp. 2980-2986, 2011. DOI: 10.1021/es102969z.

[4] Switzer, C., Pironi, P., Gerhartd, J., Rein, G. \& Torero, J., Volumetric scale-up of smoldering remediation of contaminated materials. Journal of Hazardous Materials, 268, pp. 51-60, 2014. DOI: 10.1016/j.jhazmat.2013.11.053.

[5] Scholes, G.C. et al., Smoldering remediation of coal tar contaminated soil: Pilot field tests of STAR. Environmental Science \& Technology, 2015.

DOI: 10.1021/acs.est.5b03177. 
[6] Rashwan, T.L., Gerhard, J.I. \& Grant, G.P., Application of self-sustaining smouldering combustion for the destruction of wastewater biosolids. Waste Management, 50, pp. 201-212, 2016. DOI: 10.1016/j.wasman.2016.01.037.

[7] Yerman, L., Carrascal, J., Torero, J.L., Fabris, I., Cornier, D. \& Gerhard, J.I., Smouldering combustion as a treatment for human waste. 5th International Symposium on Energy and Biomass and Waste, Venice, Italy, 2014.

[8] Kinsman, L., Torero, J. \& Gerhard, J.I., Organic liquid mobility induced by smoldering remediation. Journal of Hazardous Materials, 325, pp. 101-112, 2017. DOI: 10.1016/j.jhazmat.2016.11.049.

[9] Salman, M., Gerhard, J., Major, D., Pironi, P. \& Hadden, R., Remediation of trichloroethylene-contaminated soils by star technology using vegetable oil smoldering. Journal of Hazardous Materials, 285, pp. 346-355, 2015.

DOI: 10.1016/j.jhazmat.2014.11.042. 